\title{
SAHARAN CITY AND THE PROBLEMS OF URBAN STRUCTURE: A CASE OF THE MICRO-REGION OF SIDI OKBA, ALGERIA
}

\author{
BENSMINA LATOUI \& FARHI ABDALLAH \\ Lacomofa, Department of Architecture, University of Biskra, Algeria
}

\begin{abstract}
The services are localized according to their sector, in various territories of varying size, so the real organizational unit is constituted by all the centers necessary to provide all the services required by economic activities and the life of the population. In this research, the focus is on the micro region of Sidi Okba, Algeria. This micro regional area consists of several urban and rural centers of different population sizes, different socio-economic situations and a variety of articles related to easements and equipments. The layout of all components of the territory and their potential seem to impose a state of affairs which reflects hypothetically inconsistency and imbalance of its spatial structure which deserves to be diagnosed in order to understand the strengths and weaknesses which characterize it and correct the hiatus in order to achieve balance and consistency as sought by the government. This finding, also shared by managers at different levels of responsibility, begs various research questions: This imbalance is it related to the uneven distribution of public facilities on the centers in this micro region? Or the imbalance related to the demographic distribution of its human settlements? Or even to the poor management in terms of infrastructure and economic activities? The answer to these questions lead to poor urban planning that has been established for many years as head of the inconsistency of the urban structure of the sub-region of Sidi Okba. This research will try to highlight the reality of this spatial entity by using various techniques and analysis models such as gravity models (Reilly model), statistical demographic models (Zipf and Beckmann models) Multi-criteria models (AMC), statistical processing models, as well as the systemic approach that considers the space as an organized whole with interrelated, inter-dependent and inter-active elements of composition.
\end{abstract}

Keywords: urban structure, urban planning, micro-regional space, urban demography, urban imbalance.

\section{INTRODUCTION}

Cities can be defined today by quantitative criteria, such as demographic size, density or even the volume of market production. On the other hand, the functional definition of the city can be in its administrative status, its economic specialization or its role in the urban hierarchy or structuring of exchanges and communications.

The micro-region of Sidi Okba consists of several urban and rural centers of different demographic sizes, various socio-economic situations and a range of statutes related to easements and facilities. The disposition of all the components of the territory and their potentialities seem to impose a state of fact that hypothetically translates the incoherence and imbalance of its urban structure.

The objective of this work is to demonstrate the reality of this spatial entity by using various techniques and analysis models such as gravity models (Reilly model), statistical demographic models (Zipf and Beckmann models) Multi-criteria models (AMC), statistical processing models, as well as the systemic approach that considers the space as an organized whole with inter-related, inter-dependent and inter-active elements of composition. 


\section{METHODOLOGICAL APPROACH}

The methods most frequently used in the analysis of modern urban systems in terms of urban structure and hierarchies are: the rank-size law which emphasizes the demographic definition of the centers [1]-[4] and the multi-criteria analysis that favors the functional approach whose urban hierarchy concept includes the differentiation of the centers by their size of the services they make available to the residents and the influence they exert on the space in a given system [5]-[8].

For this, in order to better diagnose the state of the urban structure of the micro-region of Sidi Okba we will analysis the demographic distribution through the use of Zipf and Beckmann models.

About functional analysis, we will use multi-criteria analysis where a grid based on five criteria has been established; A: public facilities, B: retail, C: health, D: transport, E: zone of urban influence.

\section{DEMOGRAPHIC ANALYSIS}

The total population of the micro-region of Sidi okba is estimated at the end of the year 2016 at 81373 residents [9], distributed on 33 urban and rural centers (see Table 1) on a total area of $1627 \mathrm{~km}^{2}$.

\subsection{The Zipf model (rank/size): demographic disparity and predominance}

This distribution rule of rank/size that is applied to cities consists on classifying them according to the rank of their population, the established relationship between the population of each city and its hierarchical rank in a classification per number of residents would be constant [2]. In a landmark of dual logarithmic scale, X and Y, the curve of the ensemble of points representing the population and the rank of cities follows a line of adjustment. Any significant gap can be considered an anomaly and raises the 'why' question?

The application of rank/size model of Zipf on the ensemble of urban and rural centers of the micro region of Sidi okba shows different anomalies.

The first reading of the rank/size distribution shows exist of different gaps which are repeated each time by forming classes of population. The predominance of Sidi okba is evident not only when compared to other centers but even to the result of the line of adjustment where Sidi okba detaches slightly above the line of adjustment (see fig 1) accompanied by its two administrative centers Chetma and Ain Naga of the second class and then third class centers Drouh, Horaya and Seriana. The centers that count a population of less than 500 residents are located below the line of adjustment.

\subsection{The Beckmann model: a significant demographic deficit in intermediate and lower} ranks

The application of Beckmann model is based on the rank and dimension of the correlation between its three variables (population of the biggest city, population and rank of a given center and the demographic constant $\mu$ ). A coherent system requires that the size decreases proportionally to the next row by a constant which must have the value of 1 for the biggest city [1]. This model is simplified by eqn (1):

$$
Y n=\frac{\mathrm{x}}{\mathrm{Zn} \cdot \mu},
$$


Table 1: The population of the micro-region of Sidi Okba. (Source: Monograph of Biskra, 2016.)

\begin{tabular}{|c|c|c|}
\hline Centers & Rank & Population \\
\hline Sidi Okba & 1 & 35302 \\
\hline Chetma & 2 & 13296 \\
\hline Ain Naga & 3 & 9724 \\
\hline El-Haouche & 4 & 4076 \\
\hline Drouh & 5 & 3521 \\
\hline Horaya & 6 & 3112 \\
\hline Seriana & 7 & 2835 \\
\hline Garta & 8 & 1320 \\
\hline El-Saada & 9 & 1117 \\
\hline Sidi Khelil & 10 & 924 \\
\hline Souiket & 11 & 887 \\
\hline SMB & 12 & 805 \\
\hline Tehouda & 13 & 612 \\
\hline El-Sadra & 14 & 588 \\
\hline El-Dibia & 15 & 324 \\
\hline Zemourra & 16 & 322 \\
\hline Mansoria & 17 & 306 \\
\hline Mebdouaa & 18 & 242 \\
\hline Faid Sella & 19 & 236 \\
\hline El-Maleh & 20 & 223 \\
\hline El-Hamra & 21 & 214 \\
\hline El-Tajdid & 22 & 203 \\
\hline Alb Lagtat & 23 & 189 \\
\hline Zone Faid & 24 & 174 \\
\hline El-Nabka & 25 & 166 \\
\hline Sidi Saleh & 26 & 149 \\
\hline Mnaicef & 27 & 134 \\
\hline El-khafedj & 28 & 127 \\
\hline Trig Chegua & 29 & 123 \\
\hline El-Hmedj & 30 & 118 \\
\hline Trig Saada & 31 & 116 \\
\hline Rokna & 32 & 108 \\
\hline Alb chermat & 33 & 102 \\
\hline
\end{tabular}

where $Y n$ represents the population of a center $n, x$ is the population of the biggest city and $\mathrm{Zn}$ the rank of the center $\mathrm{n}$.

The deficit and oversized of population depends on the value of the constant $\mu$ of each center if it is greater than or less than 1 including:

- $\mu>1$ : shows a deficit.

- $\mu<1$ : shows an oversized.

- $\mu=1$ : shows coherence in the demographic distribution. 


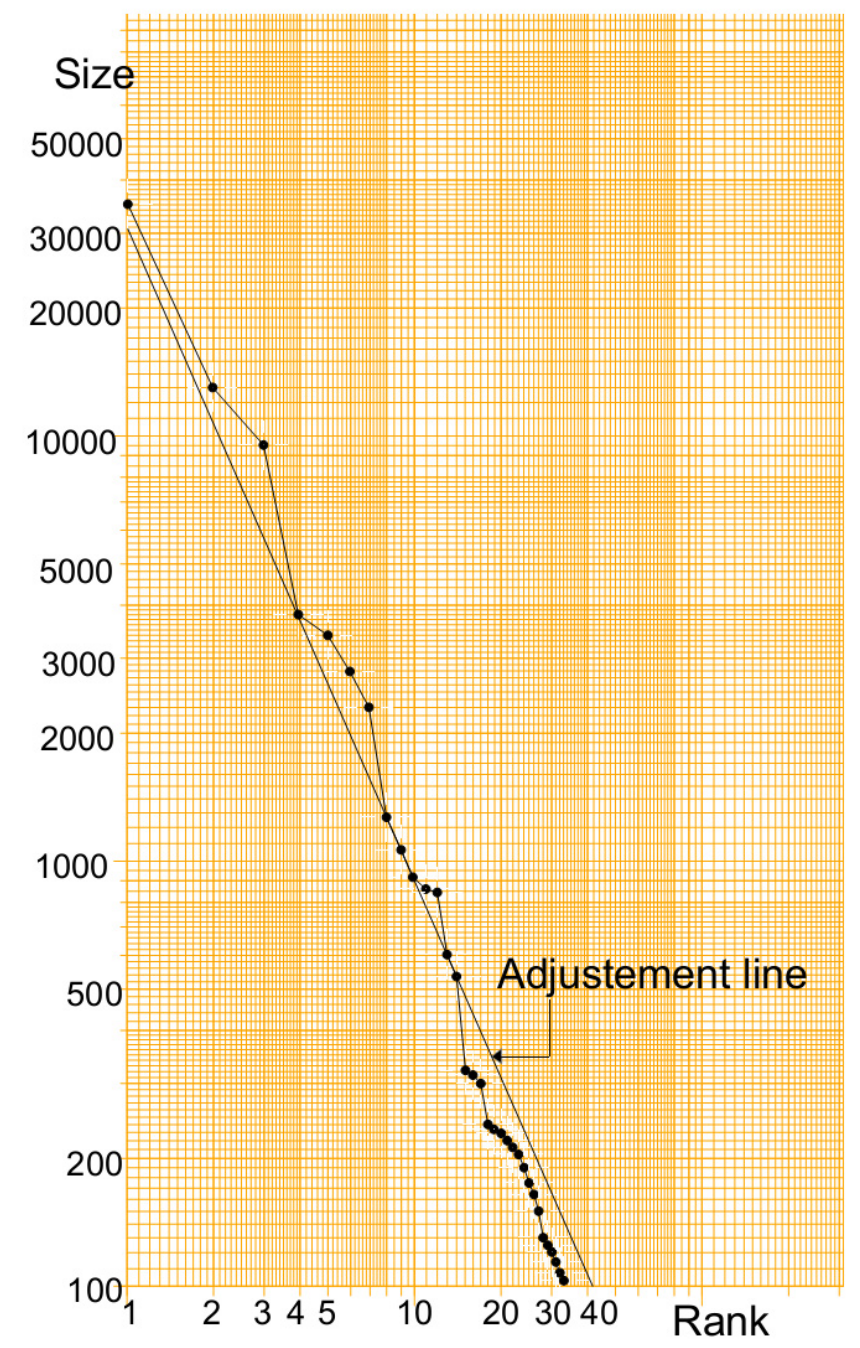

Figure 1: The distributions of the urban and rural centers of the Sidi Okba micro-region according to the Zipf model. (Source: Authors, 2017.)

Ain Naga and to a less degree Chetma that have the constants close to the unit and equal to $1.21 ; 1.32$. The rest of the centers have superior constants than 1 (see Fig. 2). This reflects the demographic deficit of all the centers compared to the population of the biggest center.

The secondary agglomerations know the largest demographic deficit of the whole microregional system of Sidi Okba with high constants that reach 10 for Alb chermat and Rokna, the other centers have constants between (1.77 and 9.97). This demographic imbalance is explained by the rurality, the absence of public facilities and infrastructure and the lack of jobs that know these centers. 


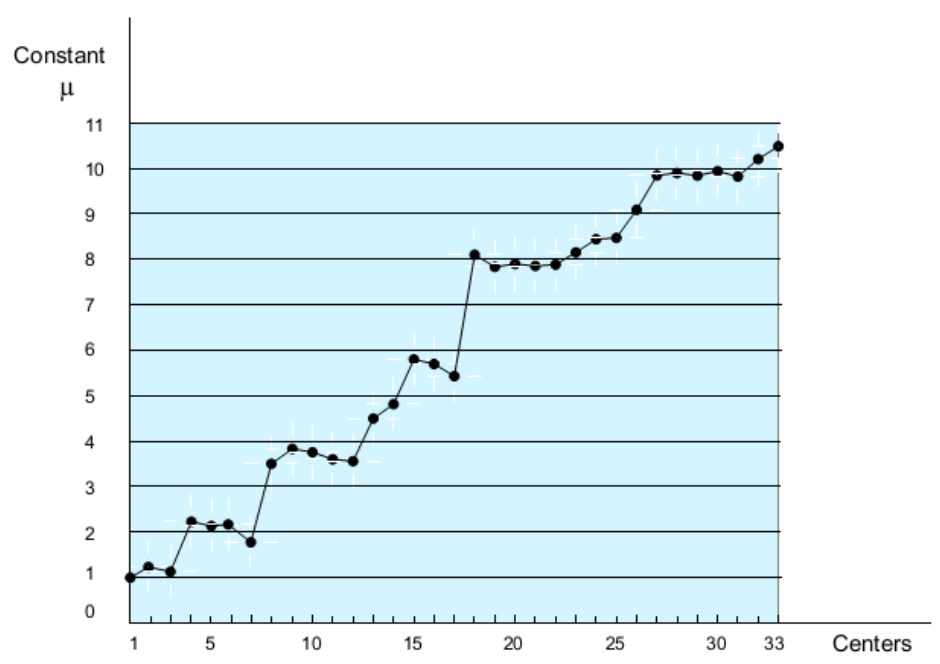

Figure 2: Hierarchy of the urban and rural centers of the Sidi Okba micro-region according to the Beckmann model. (Source: Authors, 2017.)

\section{FUNCTIONAL ANALYSIS: THE SOCIO-ECONOMIC SITUATION OF SIDI OKBA MICRO REGION}

\subsection{The distribution of public facilities}

A good distribution of public facilities is aimed at reducing individual transport, ensuring a sufficient user base for each public facility while providing the necessary services for the inhabitants and making the whole region live.

In this sense, we have set up a grid of public facilities hierarchized in six different levels gradually distributed from basic infrastructure to superior services totalling thirty-eight indicators [10] (see Table 2).

Reading the results indicates that the Sidi Okba micro-region is dominated by the center of Sidi Okba, its position at level 6 includes all urban facilities (Level $2+$ level $3+$ level $4+$ level 5), followed by Chetma, Ain Naga and El-Haouche, at the 3rd level. The absence of the secondary centers or poles at levels 4 and 5 reflects the weakness of the distribution hierarchy. In other words, the population of the lower centers (Levels 1, 2 and 3) go directly to the Sidi Okba center because they do not find centers at levels 4 and 5 for their service needs.

\subsection{Commercial concentration in the center of Sidi Okba}

The classification of the 33 centers of the Sidi Okba micro-region according to the commercial activity (traders, artisans, etc.) gives a hierarchical grid based on the number of retail trade stores per center (see Table 3 ), including six levels ranging from 01 to more than 200 stores distinguish the 33 centers which constitute the micro-region [11].

24 centers out of 33 in the Sidi Okba micro-region do not have any retail business, a fact that explains the fragility of the urban structure; only 02 centers have between 1 and 3 retail trade stores, which place them at level 2. 
Table 2: Hierarchical grid of existing functional public facilities. (Source: M. Cote, 1982, A. Farhi, 2001 and reformulated by Authors, 2017.)

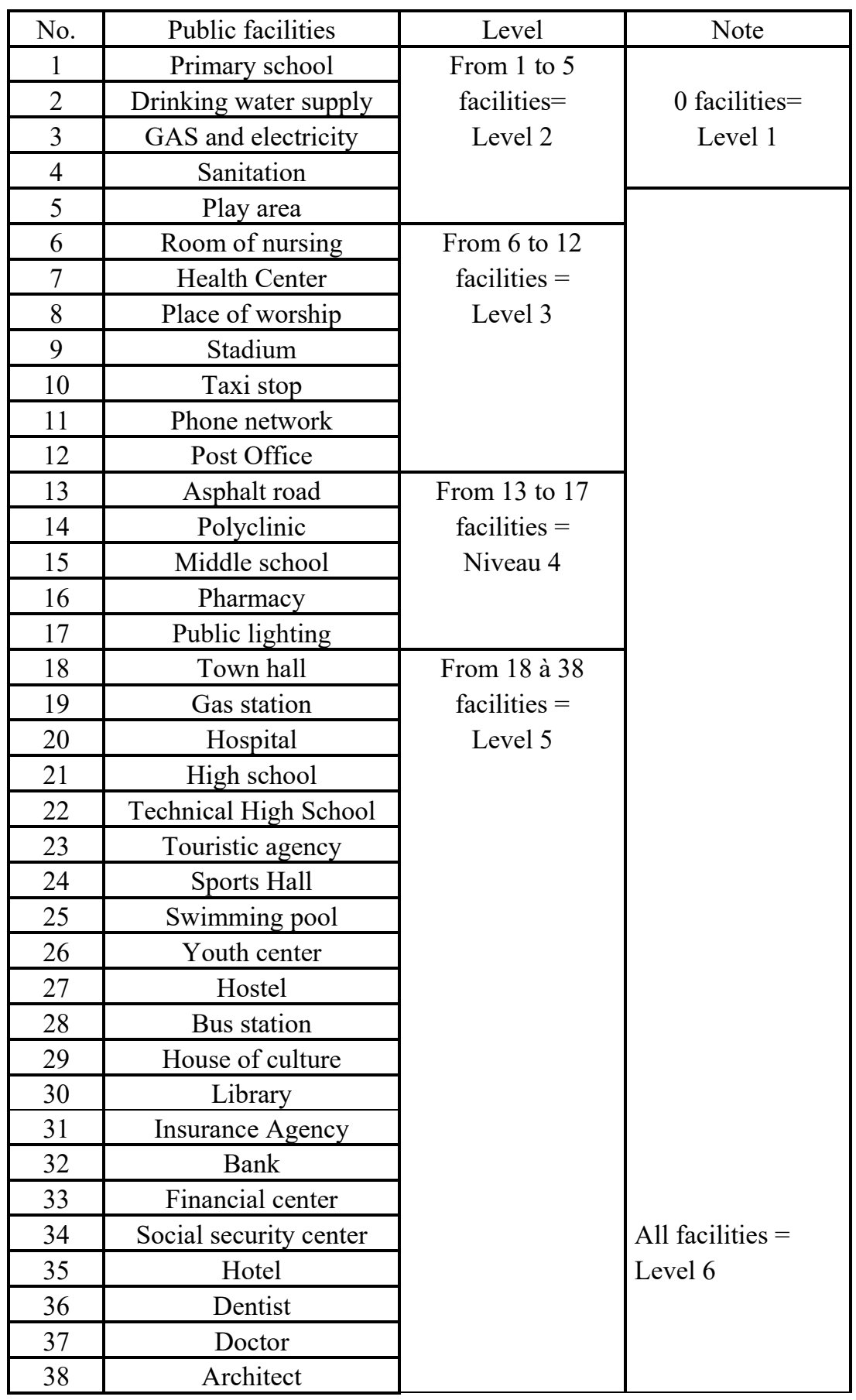


The commercial sector is dominated by the center of Sidi Okba, which has more than 200 retail trade stores ( $69 \%$ of the total). A single Chetma center plays the second role with 143 retail trade stores, which places it at level 5, at this level appears the weakness of the urban structure of the micro-region of Sidi Okba because only one center plays the secondary role, in spite of its remote distance from the other centers.

\subsection{Very unequal distribution of health facilities and medical staff}

The center of Chetma has a population of 13296 residents and it regroups 4 doctors distributed in 2 polyclinics, whereas the center of El-Haouche has a population of 4176 inhabitants and it gathers 2 doctors and two polyclinics.

The center of Sidi Okba is at level 6 with a rate of 1 doctor per 1000 residents that is to say 29 doctors for 35302 residents distributed in 4 polyclinics and a service of the surgical emergencies. 17 centers in the Sidi Okba micro-region or 7310 residents have no doctor, which places them at level 1, level 2 and 3 are empty, a break that reflects the inconsistency of the urban structure of the micro-region of Sidi Okba (see Table 4).

The distribution of medical staff is very unequal geographically. Some urban centers have a medical density of less than 5 doctors for 13296 residents, others have a density greater than 2 doctors for 4176 inhabitants.

Table 3: Hierarchy of the 33 centers according to the distribution of trade. (Source: Authors, 2017.)

\begin{tabular}{|c|c|c|}
\hline Levels & Trade & Number of centers \\
\hline 1 & 0 & 24 \\
\hline 2 & 1 to 3 & 2 \\
\hline 3 & 5 to 20 & 4 \\
\hline 4 & 20 to 100 & 1 \\
\hline 5 & 100 to 200 & 1 \\
\hline 6 & More than 200 & 1 \\
\hline
\end{tabular}

Table 4: Medical staff and health facilities. (Source: Authors, 2017.)

\begin{tabular}{|c|c|c|c|c|c|c|}
\hline Level & Medical staff & \multicolumn{4}{|c|}{ Health facilities } & Nbr of centers \\
\hline & Doctor/1000 residents & T.R & C & $y$ & gency & \\
\hline 1 & 0 & 0 & 0 & 0 & 0 & 17 \\
\hline 2 & 0 & 1 & 0 & 0 & 0 & 11 \\
\hline 3 & 0 & 0 & 1 & 0 & 0 & 1 \\
\hline 4 & 1 doctor $/ 4000$ residents & 1 & 0 & 1 & 0 & 1 \\
\hline 5 & 1 doctor $/ 2000$ residents & 1 & 0 & 2 & 0 & 2 \\
\hline 6 & 1 doctor/1000 residents & 2 & 1 & 4 & 1 & 1 \\
\hline
\end{tabular}




\subsection{A weakness in public transport link}

In order to classify the 33 urban and rural centers which constitute the micro-regional Sidi Okba area according to the transport criteria, a grid was established based on the number of directions per center and the number of operators, these two indices are related to a third one, that of movement per day because when the number of directions and the number of operators increase the movements per day increase and the centers become more accessible.

The center of Sidi Okba is linked to the centers of Chetma, El-haouche, Horaya, Ain Naga and Sidi Khelil by means of 05 transport lines, of which 10 operators daily make more than 4 movements $(1$ movement $=$ round trip). This places it alone at level 6 .

No center is at levels 4 and 5. At level 3 there are Ain Naga and Chetma, each center has 2 directions, the number of operators is between 1 and 3 with 2 movements per day.

At level 2 there are Drouh, Seriana, Horaya, Sidi Khelil and El-Haouche with only one direction per center, one operator and one movement per day.

28 centers out of 33 which constitute the micro-regional space of Sidi Okba are completely isolated from the transport network which explains the absence of the secondary poles in levels 4 and 5 (see Table 5).

\subsection{Zone of urban influence}

According to Reilly [12], the influence (I) of a center is proportional to its weight (P) and inversely proportional to the square of the distance (D) which separates it from another given center:

$$
I=\frac{\mathrm{P}}{\mathrm{D}^{2}}
$$

The hierarchy by level of the different centers according to the criteria of urban influence by public facilities, retail trade and services has highlighted the four types of attraction (Att $>75 \%, 75 \%>A t t>50 \%, 50 \%>A t t>25 \%, A t t<25 \%)$, which show different levels of functioning of the micro-regional space of Sidi Okba (see Fig. 3).

The center of Sidi Okba is at level 5, followed by Chetma, Ain Naga, El-Haouche, ElSaada, Souiket and El-Sadra on level 2. The rest of the centers are at level 1. No centers occupy levels 3 and 4 . This represents a hiatus to consider.

Table 5: The levels of connection to the transport network. (Source: Authors, 2017.)

\begin{tabular}{|c|c|c|c|c|}
\hline Level & Nbr of direction & Nbr of operators & Movement per day & Nbr of centers \\
\hline 1 & 0 & 0 & 0 & 25 \\
\hline 2 & 1 & 1 & 1 & 5 \\
\hline 3 & 2 & 1 to 3 & 2 & 2 \\
\hline 4 & 3 & 3 to 5 & 3 & 0 \\
\hline 5 & 4 & 5 to 10 & more than 4 & 1 \\
\hline 6 & more than 4 & more than 10 & & \\
\hline
\end{tabular}




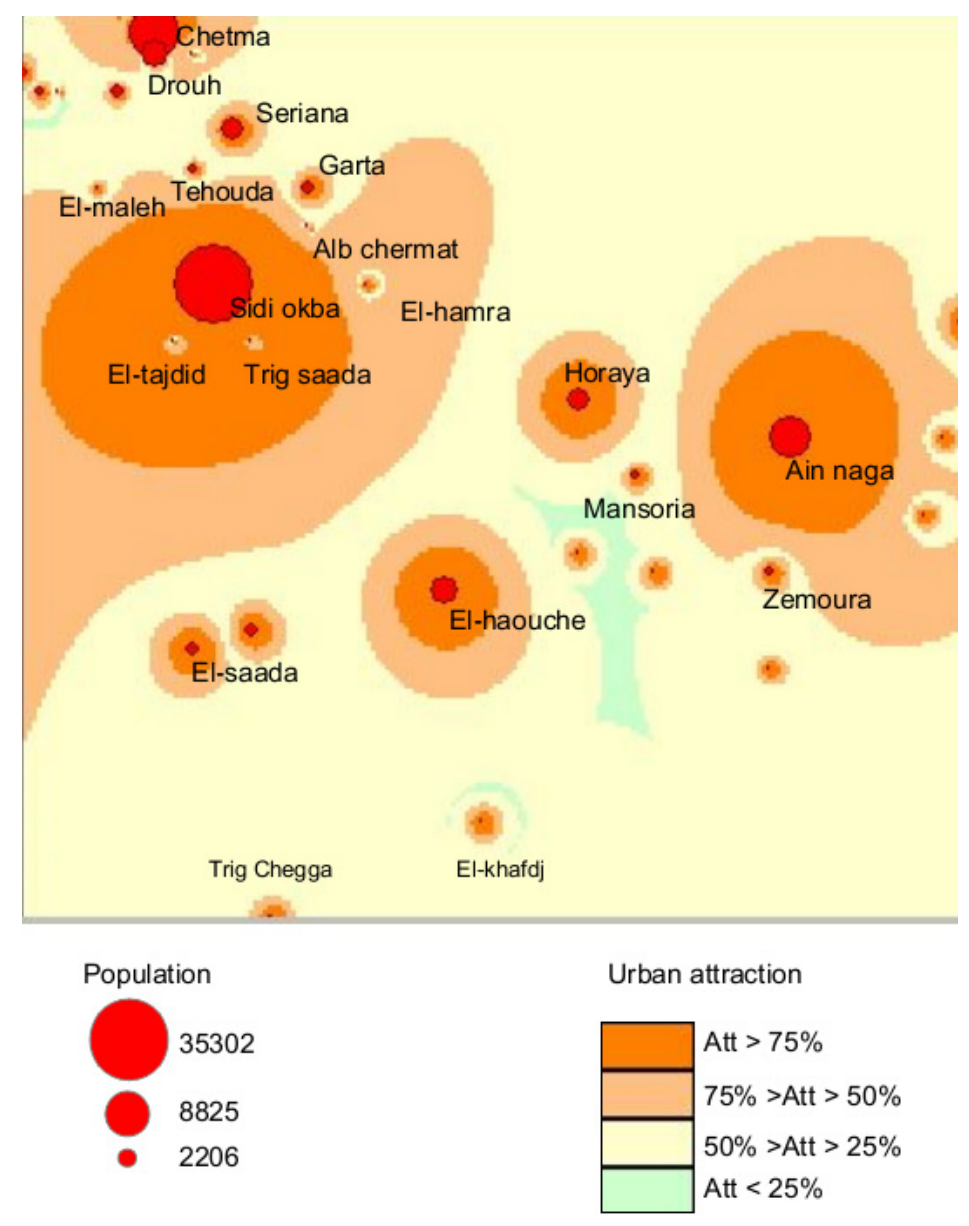

Figure 3: The areas of urban influence according to the Reilly model. (Source: Authors, 2017.)

\section{DISCUSSION}

The superposition of the results of the criteria applied to Sidi Okba's micro-regional system (A: public facilities, B: retail, C: health, D: transport, E: zone of urban influence) draw up a synoptic table (see Table 6).

This multi-criteria systemic analysis has enabled us to identify the synthetic level pyramid (see Fig. 4).

The reading of the pyramid shows three important facts: the incontestable domination of the center of Sidi Okba, a break between levels 6 and 3, reflected in the absence of the centers at level 5 and 4, which reflects the weakness of intermediate relays and a very large base occupied by three-quarters (3/4) of the centers of the micro-regional system.

The micro-regional system of Sidi Okba is clearly unbalanced, the absence and weakness of the relay centers leaves the center of Sidi Okba receiving thousands of residents to satisfy their needs for services, the concentration of public facilities in one center polarizes the corresponding system. 
Table 6: Hierarchy of centers by levels. (Source: Authors, 2017.)

\begin{tabular}{|c|c|c|c|c|c|c|c|}
\hline Center & $\mathrm{A}$ & $\mathrm{B}$ & $\mathrm{C}$ & $\mathrm{D}$ & $\mathrm{E}$ & Tot & Level \\
\hline Zone Faid & 1 & 1 & 1 & 1 & 1 & 5 & 1 \\
\hline El-Hmedj & 1 & 1 & 1 & 1 & 1 & 5 & 1 \\
\hline Trig Chegga & 1 & 1 & 1 & 1 & 1 & 5 & 1 \\
\hline Alb Lagtat & 1 & 1 & 1 & 1 & 1 & 5 & 1 \\
\hline Mnaicef & 1 & 1 & 1 & 1 & 1 & 5 & 1 \\
\hline Faid sela & 1 & 1 & 1 & 1 & 1 & 5 & 1 \\
\hline Sidi Saleh & 1 & 1 & 1 & 1 & 1 & 5 & 1 \\
\hline Mebdouaa & 1 & 1 & 1 & 1 & 1 & 5 & 1 \\
\hline Alb chermat & 1 & 1 & 1 & 1 & 1 & 5 & 1 \\
\hline El-Maleh & 1 & 1 & 1 & 1 & 1 & 5 & 1 \\
\hline El-Tajdid & 1 & 1 & 1 & 1 & 1 & 5 & 1 \\
\hline Trig Saada & 1 & 1 & 1 & 1 & 1 & 5 & 1 \\
\hline Nabka & 1 & 1 & 1 & 1 & 1 & 5 & 1 \\
\hline Mansoria & 2 & 1 & 1 & 1 & 1 & 6 & 1 \\
\hline Zemourra & 2 & 1 & 1 & 1 & 1 & 6 & 1 \\
\hline El-Hamra & 2 & 1 & 1 & 1 & 1 & 6 & 1 \\
\hline Souiket & 2 & 1 & 1 & 1 & 2 & 7 & 1 \\
\hline Rokna & 2 & 1 & 2 & 1 & 1 & 7 & 1 \\
\hline Khafdj & 2 & 1 & 2 & 1 & 1 & 7 & 1 \\
\hline SMB & 2 & 1 & 2 & 1 & 1 & 7 & 1 \\
\hline Dibia & 2 & 1 & 2 & 1 & 1 & 7 & 1 \\
\hline Tehouda & 2 & 1 & 2 & 1 & 1 & 7 & 1 \\
\hline Garta & 2 & 3 & 1 & 1 & 1 & 8 & 1 \\
\hline Elsadra & 2 & 1 & 2 & 1 & 2 & 8 & 1 \\
\hline Horaya & 2 & 2 & 2 & 2 & 1 & 9 & 1 \\
\hline Seriana & 2 & 2 & 2 & 2 & 1 & 9 & 1 \\
\hline Sidi Khelil & 2 & 1 & 3 & 2 & 1 & 9 & 1 \\
\hline El-saada & 2 & 3 & 2 & 1 & 2 & 10 & 2 \\
\hline Drouh & 2 & 3 & 2 & 2 & 1 & 10 & 2 \\
\hline El-haouche & 3 & 3 & 5 & 2 & 2 & 15 & 3 \\
\hline Ain Naga & 3 & 4 & 4 & 3 & 2 & 16 & 3 \\
\hline Chetma & 3 & 5 & 5 & 3 & 2 & 18 & 3 \\
\hline Sidi Okba & 6 & 7 & 6 & 6 & 5 & 30 & 6 \\
\hline & & & & & \\
\hline
\end{tabular}




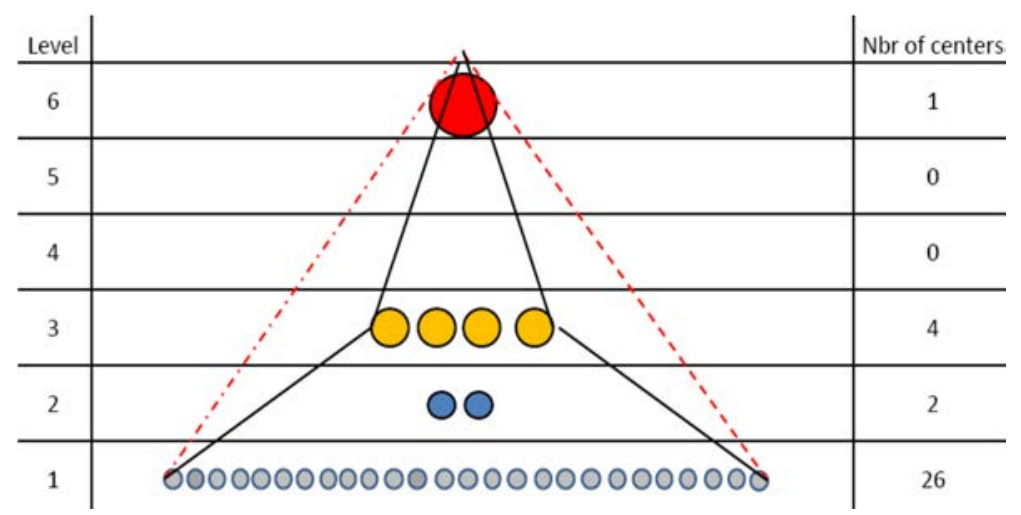

Figure 4: The pyramid of the levels of the centers of the micro-region of Sidi Okba. (Source: Authors, 2017.)

\section{CONCLUSION}

In the light of what has been analyzed, we can deduce that the demographic analysis and functional analysis agree on one and the same principle: the incoherence of Sidi Okba's micro-regional system. The centers and agglomerations have not amortized the demographic deficit with the center of Sidi Okba and have allowed the micro-regional system to be increasingly unbalanced. Research based on systemic vision allows us to have an idea of the strengths and weaknesses of a given space. The application of this approach to Sidi Okba's micro-regional system has shown the concentration of facilities, activities and services within the center of Sidi Okba, the absence of secondary centers or relayers that can support this center by constituting a passage relative to the needs of the populations of the other centers causes an imbalance of the urban structure at all levels.

\section{ACKNOWLEDGEMENT}

Authors would like to express deeply gratitude to laboratory LACOMOFA, Department of Architecture, University of Biskra, Algeria.

\section{REFERENCES}

[1] Beckmann, M., Structural proportions in a hierarchy of cities, Economic Development and Cultural Change, New York, 1958.

[2] Zipf, G.K., Human behaviour and the principle of least effort, Adisson Wesly: Boston, p. 573, 1945.

[3] Pumain, D.A., Geographical Theory for the Law of Zipf. Region and Development Journal, 36, pp. 32-54, 2012.

[4] Dimou, M. \& Schafar, A., Evolution of urban hierarchies and Zipf law: the case of the Balkans. Region and Development Journal, 2, pp 66-86, 2007.

[5] Medareg Narou B., \& Farhi, A., The role of services and investments in the hypertrophy of the city of El Oued in the lower Algerian Sahara. Urban Environment, 3, pp. 1-18, 2009.

[6] Rochefort, M., Methods of study of urban networks: interest of the analysis of the tertiary sector of the active population. In Annals of Geography, 66, 354, pp. 125-143, 1957. 
[7] Rozenblat, C. \& Cicille, P., European cities: comparative analysis. On the Waterfront. Public Art. Urban Design. Civic Participation. Urban Regeneration, pp. 1-94, 2004.

[8] Abdallah, F., Macrocephaly and poles of balance: the wilaya of Biskra. The Geographical Space, 30, pp. 245-255, 2001.

[9] Monograph of Biskra, Report of statistics related to population and public facilities, 2016.

[10] Cote, M., Methodology of approach, Rhumel, Constantine, 1982.

[11] Davies, W.K.D. \& Berry, B.J.L., Geography of market centers and retail distribution. Progress in Human Geography 16, pp. 219-222, 1992.

[12] Reilly, W., The law of retail gravitation, the knickerbockers press, New York, 1931. 